Vol. 4, Issue 1, July 2021

\title{
Examining the Effects of a Peer-Learning Research Community on the Development of Students' Researcher Identity, Confidence, and STEM Interest and Engagement
}

\author{
Bon W. Koo ${ }^{1 *}$, Shruti Bathia ${ }^{2}$, Linda Morell2 ${ }^{2}$ Perman Gochyyev², Michelle Phillips ${ }^{3}$, Mark Wilson², and Rebecca \\ Smith $^{4}$
}

*These authors contributed equally to this work.

${ }^{1}$ Science Education for Public Understanding Program, Lawrence Hall of Science, UC Berkeley, Berkeley, CA; ${ }^{2}$ Berkeley Evaluation and Assessment Research

Center, Graduate School of Education, UC Berkeley, Berkeley, CA; ${ }^{3}$ Phillips and Associates, San Francisco, CA; and ${ }^{4}$ Science and Health Education Partnership,

UC San Francisco, San Francisco, CA

Keywords: STEM development, peer communities, researcher identity, identity, public health, Youth Participatory Action Research, research experience,

high school

Publication Date: July 9, 2021

DOI: https://doi.org/10.15695/jstem/v4i1.05

\begin{abstract}
While the impact of authentic research experiences in STEM on student engagement and interest in science has been documented, less is known about the role of peer communities in fostering this interest and engagement. This research explores the idea that a strong peer community can catalyze deep learning and engagement in scientific research among high school students. The program engaged 20 high school students in a year-long community-based participatory research project in public health each year. The study used a mixed methods approach, combining data from focus group discussions, observations, and surveys to describe the program's impact on participants. Analysis across three years reveals that (a) the program was associated with a statistically significant shift in students' identity as researchers, with a medium growth effect size (Cohen's d) for the second and third years, which moderated by the end of the program, and (b) the peer community played a central role in the participants' engagement in the program, on their identity as researchers, and strengthened their interest in STEM. These findings convey the importance of designing STEM experiences that build strong peer communities around science practices and how such communities can have profound impacts on students' identities in STEM.
\end{abstract}

\section{INTRODUCTION}

Learning through Community. Lave and Wenger (1991) describe learning as a quintessentially social process and acknowledge that learning frequently takes place in the context of a community. Learning communities may be made up of groups with a wide variety of interests, such as in a school environment, or may consist of groups with a common interest in a subject or topic and who collaborate over an extended period of time. Lave and Wenger defined the latter as a community of practice, and these are known to play an important role in students' career and identity development (Aschbacher et al., 2010). Communities of practice provide opportunities for both formal and informal apprenticeships in which students learn the shared language of a field, participate in its rituals, and learn the stories and histories val- ued within a given community. Students' experiences are informed by the social interactions within the community that may occur between students and their peers, with teachers and/or with mentors who are themselves members of the community; and these interactions both with members of the community as well as those outside of it, including students' parents, help shape students' perception of a field and their place within it (Eccles et al., 1983).

In the context of science learning, classroom science is the most common community of practice in which students participate. While nearly every student will experience science in a school setting, the quality of these experiences varies greatly. In their longitudinal study, Aschbacher et al. (2010) found that $45 \%$ of students who reported a very strong 
interest in a STEM major or career in 10th grade had lost that interest by 12th grade. Notably, the majority of the students who lost interest in STEM were from schools serving lowincome student populations. For these students, schools, teachers, and counselors failed to encourage their science interests. According to Aschbacher et. al (2010), the students reported that science learning was not a priority, instruction was poor, and they were subjected to a boring curriculum with few hands-on opportunities. Students' interest in STEM was further eroded by dual pressures - that of counselors serving as gatekeepers to advanced STEM courses and the students' own faltering confidence in their STEM abilities as courses became more difficult (Aschbacher et al., 2010).

Many fewer students, particularly among those from backgrounds underrepresented in science, have access to out-of-classroom science enrichment experiences such as an internship in a research laboratory (Aschbacher et al., 2010). These kinds of opportunities immerse students in a professional community of practice in the form of an apprenticeship in which the students work directly with practicing scientists. Through this experience, students gain direct experience with the tools and practices of science, develop relationships with science role models from different backgrounds and at different stages across the educational and career continuum, and begin to learn the language and cultural practices of the field of science. These enrichment opportunities are powerful, and numerous papers have reported on the benefit of these types of experiences on students' interest in science and their resultant further pursuit of STEM degrees and careers (Salto et al., 2014; Rohrbaugh and Corces, 2011; Kabacoff et al., 2017; Witzel et al., 2020).

While these immersive research experiences can play an important role in shaping students' identities and interest in STEM, their structure is one that promotes assimilation into the culture of science, which is centered in dominant western cultural narratives and perspectives. This can be problematic for students from non-dominant communities whose cultural histories and perspectives are often not represented in STEM. The cultural bias of traditional STEM and sociopolitical history results in many youth from these backgrounds feeling as though they don't belong in STEM careers (Aikenhead, 2001; Lee, 2011). It is therefore critical that students have STEM experiences that leverage their lived experiences and existing funds of knowledge and connect their participation in science with their identity in their home communities (Brickhouse and Potter, 2001). Thus, we were interested in understanding how engaging students in a different type of research experience, one that focused on building a strong student community and that explicitly recognizes and celebrates students' knowledge of their communities and cultures, might contribute to students' development of a researcher identity.
Researcher Identity. Existing social, cultural, and historical biases about what science is, who can do science, who science is for, and who can be a scientist may limit students' willingness to consider a science identity for themselves. For example, in a large study exploring the determinants of science identity in a middle school population, Hill et al. (2018) found that equal proportions of students, regardless of gender or race/ethnicity, had a "discovery orientation" meaning they enjoyed taking things apart to see how they work and were curious about nature. However, when survey items in the study specifically included the word "science" there were significant disparities in responses among students of different genders and race/ethnicities. Thus, to avoid this negative effect, we decided not to focus on "science identity" in our study.

Students' perceptions of science are largely defined by their experiences in science in school and from the media thus while students recognize a physicist or a laboratory setting as being related to science, they are less likely to realize that there are careers in science that involve analyzing large data sets on a computer, or that there are careers for people interested in working to improve the health of their community that use tools such as survey-based research prevalent in public health. Thus, we hypothesized that probing students' "researcher identity" might minimize the possibility that students would draw on a preexisting stereotype that did not include images within their identity schema and would allow for a broader range of potential roles to be consistent with this identity. We developed an instrument to measure students' researcher identity using the BEAR Assessment System and conducted investigations to establish its validity and reliability. This instrument is described in more detail in the methodology section below.

San Francisco Health Investigators. The San Francisco Health Investigators (SFHI) program was developed by the Science and Health Education Partnership (SEP) at the University of California, San Francisco (UCSF) in partnership with the Berkeley Evaluation and Assessment Research (BEAR) Center at the University of California, Berkeley. Core to the SFHI program is a youth participatory action research (YPAR) model, a variation of community-based participatory research (CBPR) that centers youth as co-researchers. Each year, the program engaged a cohort of up to 20 high school students from diverse backgrounds, the majority of whom were considered underrepresented in the biomedical sciences, based on the NIH's definition, to conduct research into health issues of relevance to their communities. The health topic varied each year and focused on current and emerging public health issues such as infectious disease and immunity (with a Zika focus in year one), antibiotic resistance (in parallel with the World Health Organization's World Antibiotic Resistance Awareness Week in year two), 
and the health disparities surrounding cancer diagnosis and prevention in year three. Students utilized data they gathered from surveys they conducted in their communities and combined this information with their cultural knowledge gained from lived experiences to develop targeted health messaging campaigns designed to increase awareness and impact behavior change in their communities. Students subsequently evaluated the efficacy and impact of their health messages and shared their findings with community members, scientists, and health professionals in a culminating symposium.

SFHI was led by a team of Academic Coordinators from the UCSF SEP. All three of the Coordinators had completed doctoral degrees in the sciences and had extensive experience working in schools or informal learning environments with a focus on working in and with programs that promote access to careers in science for students from backgrounds underrepresented in the sciences. One of the Coordinators had experiences as a multi-racial first-generation college student, and another experienced the American educational system from the perspective of an immigrant and English Learner. All three came from low-income backgrounds. Each summer, the Coordinator team included a diverse group of UCSF scientists and health professionals in the program so that students could interact with a wide array of role models, learning not only from their work in science and health, but also from their stories and about their path to their careers. Students also worked closely with our graphic designer team as they crafted their health messages. The design team leader also serves as an Adjunct Professor of Cultural Studies and Social Justice at San Francisco State University, and her work with the students interwove expertise in design and critical cultural theory to encourage and promote student voices and cultural expertise in the design of the program's health messages. In year three, the design team included an intern, a first-generation college student from a low-income family, who played a key role in intentional community building with the group and served as a near peer mentor to students. Through SFHI, students worked closely with an independent college counselor, a Latina, first generation college graduate. Her sessions served to demystify the college and financial aid application process and helped students to develop their college lists, while also authentically addressing the concerns of immigrant parents. Finally, the program actively encouraged students to take on the role of co-designers within the program. In each program year, students engaged in articulating the community norms, daily reflections informed the next day's activities, and they worked collectively to develop surveys and translate them into their native languages, identify locations at which to survey community members, and were responsible for developing the creative strategy for their health message campaigns, leveraging their own voices and placing explicit value on students' cultural expertise.

In any given year, the program began with a four-week
Summer Intensive where students met daily to learn the science behind the health topic of focus, and to receive training to conduct human subjects research, design and conduct survey/interview research in their communities, and analyze their results to understand health awareness and behaviors. The Summer Intensive culminated with the development of health messaging campaign ideas that students pitched to the cohort and other health professionals and researchers, ultimately reaching a group consensus on a single campaign direction.

In addition to the research and campaign development, the Summer Intensive also played a critical role in developing and strengthening relationships within the cohort of student researchers and included a series of daily activities to facilitate community building. In the first year of the program, community building activities were limited to the first two days of the Summer Intensive and included an icebreaker activity that integrated learning about infectious disease transmission, small group discussions, and the cooperative board game Pandemic, followed by one-time weekly group lunch activities, which were co-designed with students. Feedback from students and staff observations both indicated that this was insufficient and in subsequent years, the first thirty-minutes of each day was dedicated to community building activities. These activities were explicitly designed to build connection across differences, develop trust among cohort members, and to create and sustain an inclusive environment that valued the voice of all members. In year three, we brought in program alumni to serve as Peer Leaders, and one of their roles was to design and lead community building activities with the group. In years two and three we also integrated a resiliency curriculum into the Summer Intensive to help students articulate their strengths and values, recognize the support networks extant in their lives, and learn to leverage their strengths, values, and support to achieve their goals.

Following the Summer Intensive, students met monthly on weekends to continue to develop their campaigns in preparation for a launch at a large public science event that draws over 30,000 people as part of the Bay Area Science Festival. Figure 1 shows example health messages that the cohorts created in each of the program years described in this paper. After the launch, students continued to disseminate their health messaging campaigns both in person and through digital platforms, and also gathered efficacy data on their campaign messages. The program ended in May with an end-of-program symposium where students presented their research findings and health messaging campaigns to members of their families, peers, teachers, health professionals and research scientists.

The program's goals included increasing students'1) knowledge of science content, 2) knowledge of ethical and methodologically-sound research processes and practices, 3 ) 

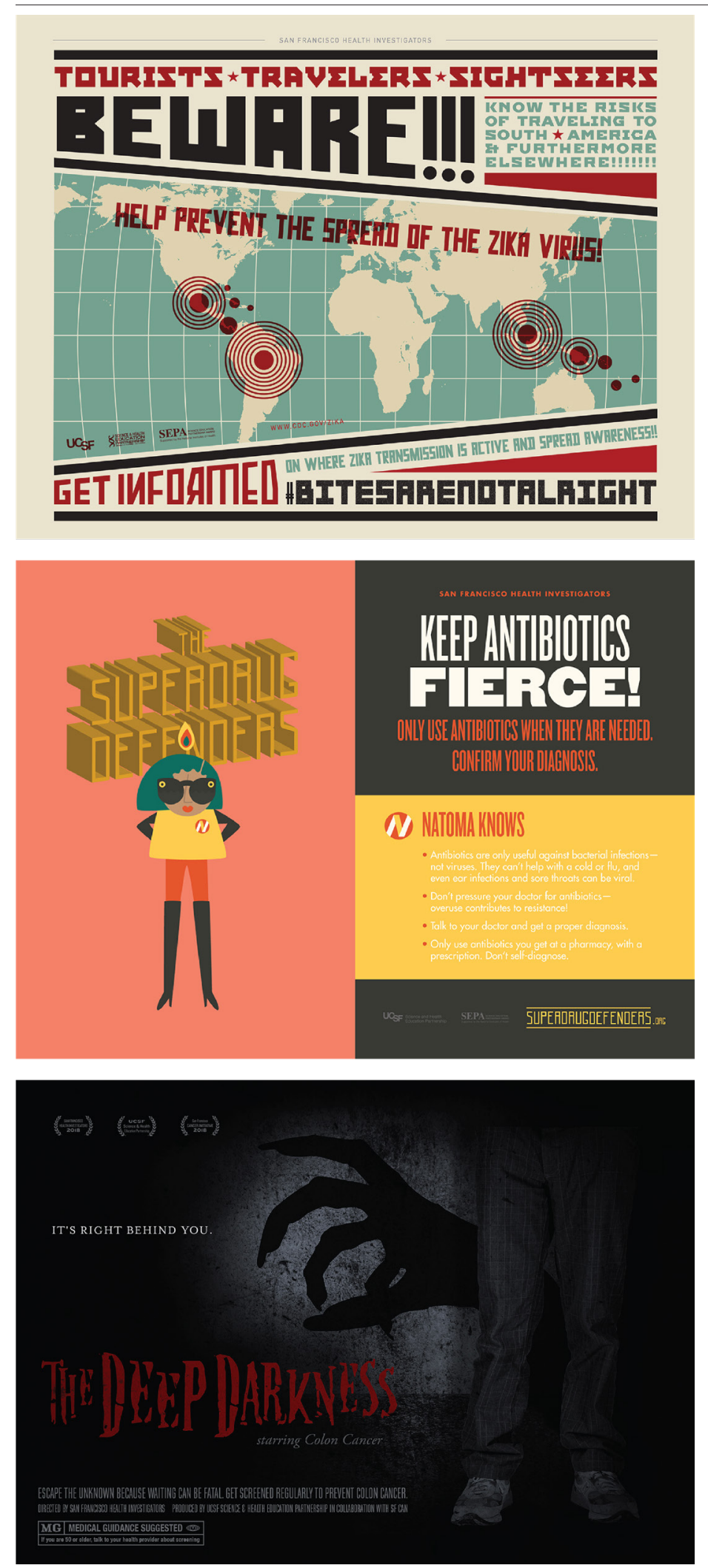

Figure 1. Sample Health Messaging Campaign Materials. Additional campaign materials may be found at: https://sep.ucsf.edu/ hs_programs/sf-health-investigators/.

awareness of career options in the health sciences, as well as 4) their confidence and self-efficacy in science generally and research specifically. Long-term, the program aimed

to increase students' interest and persistence in health science fields, and to empower students to be able to take research-based actions to improve their lives and their communities.

\section{RESEARCH QUESTIONS}

We developed a programmatic model that positioned students as researchers and immersed them in a community of practice focused on public health and science, where peerto-peer interaction and learning were central features. We set out to understand the impact of such a model on the development of students' researcher identity and their confidence and engagement in STEM.

This paper focuses on the research outcomes of this project. Specifically, we wanted to understand how the SFHI program impacted students in the following four ways:

1. Self-identification as a researcher

2. Sense of belonging to a community

3. Confidence and self-efficacy in science and research

4. Engagement and interest in science and research

\section{METHODS}

Participants. Our research sample included 56 participants across three program years. Two students from the program cohorts were not included in the Researcher Identity Scale data analysis because we were unable to match their prepost surveys. Retention in the program was very high, with 97\% (58/60) of students who enrolled in the program completing all program activities and requirements. All of the participants were high school students aged 16 to 18 who began our program during the summer between their sophomore and junior year of high school. The students were selected through a competitive application process that called on teachers in a large urban school district in California to nominate students to apply for positions in the program. We have found that this diversifies our applicant pool as teachers "tap" students who may not initially see themselves as viable candidates, encouraging them to apply. Not only does this process identify students who may not pursue a science research experience on their own, it gives students who have faced obstacles in the past an opportunity to move beyond those challenges. Moreover, the nomination itself has the potential to impact STEM self-efficacy and spark new interest in science research, as students are recognized by their teachers for their potential in STEM. Students submitted written applications and participated in in-person interviews to be selected for the program. While selection criteria required students express an interest in and curiosity about science, program recruitment materials explicitly stated that partici- 
Table 1. Race/Ethnicity of Study Participants.

\begin{tabular}{|c|c|c|c|c|c|c|c|c|c|c|c|c|c|c|c|}
\hline & $\begin{array}{l}\text { African- } \\
\text { American/ } \\
\text { Black }\end{array}$ & $\begin{array}{l}\text { American } \\
\text { Indian/ } \\
\text { Alaska } \\
\text { Native }\end{array}$ & $\begin{array}{l}\text { Native } \\
\text { Hawaiian/ } \\
\text { Pacific } \\
\text { Islander }\end{array}$ & $\begin{array}{l}\text { Chinese/ } \\
\text { Chinese- } \\
\text { American }\end{array}$ & $\begin{array}{l}\text { Japanese/ } \\
\text { Japanese- } \\
\text { American }\end{array}$ & $\begin{array}{l}\text { Vietnamese/ } \\
\text { Vietnamese- } \\
\text { American }\end{array}$ & $\begin{array}{l}\text { East } \\
\text { Indian/ } \\
\text { Pakistani }\end{array}$ & $\begin{array}{l}\text { Filipino/ } \\
\text { Filipino- } \\
\text { American }\end{array}$ & $\begin{array}{l}\text { Other } \\
\text { Asian }\end{array}$ & $\begin{array}{l}\text { Hispanic/ } \\
\text { Latino }\end{array}$ & $\begin{array}{l}\text { White/ } \\
\text { Caucasian }\end{array}$ & $\begin{array}{l}\text { Middle } \\
\text { Eastern }\end{array}$ & Other & $\begin{array}{l}\text { Decline } \\
\text { to State }\end{array}$ & $\begin{array}{l}\text { Multiethnic } \\
(2+)\end{array}$ \\
\hline \# Students (\%) & $7(12 \%)$ & 0 & 0 & $12(21 \%)$ & 0 & 0 & $1(2 \%)$ & $3(5 \%)$ & 0 & $18(31 \%)$ & $2(3 \%)$ & $2(3 \%)$ & 0 & $1(2 \%)$ & $12(21 \%)$ \\
\hline $\begin{array}{l}\text { Multiethnic } \\
\text { Students }\end{array}$ & 2 & 2 & 2 & 4 & 1 & 3 & 1 & 0 & 1 & 5 & 1 & 1 & 1 & 0 & - \\
\hline Total (\%) & $9(16 \%)$ & $2(3 \%)$ & $2(3 \%)$ & $16(28 \%)$ & $1(2 \%)$ & $3(5 \%)$ & $2(3 \%)$ & $3(5 \%)$ & $1(2 \%)$ & $23(40 \%)$ & $3(5 \%)$ & $3(5 \%)$ & $1(2 \%)$ & $1(2 \%)$ & \\
\hline
\end{tabular}

Note: Total sums to greater than $100 \%$ as 12 students indicated more than one ethnicity.

pation was an opportunity to explore science and health, and students need not be already committed to science majors or careers in this field. As such, students were not asked their career interests on the application. Of the students who volunteered career goals in their cover letter, $42 \%$ expressed interest in science or health careers and 7\% expressed that one of the things that drew them to the program was the opportunity to explore STEM fields in more depth than allowed at school. Other students expressed interest in law, fashion, graphic design and photography, and with many expressing an interest in social justice.

Table 1 shows the race/ethnicity of students participating in SFHI across the cohorts included in this study. At least $60 \%$ of students across the three cohorts came from families where neither parent had a college degree, and another $10 \%$ report not knowing if their parent(s) attended or completed college. Many of the students are themselves or have parents who are immigrants, most meet Federal definitions of low-income, at least two of the students have experienced homelessness, others in the study have incarcerated parents or siblings and/or are from families impacted by gun violence.

Research Identity Instrument. The Researcher Identity Scale (RIS) was developed to evaluate the influence of the SFHI program model on students' researcher identity. The RIS was developed using the BEAR Assessment System, BAS, (Wilson, 2005) and the instrument development and validation is described in more detail in Morell et al. (2020) and Bathia et al. (2020). Notably, assessment development using the BAS is iterative, and the assessment instrument is closely aligned to a construct map - an ordering of qualitatively different levels of the feature of interest. Thus, the RIS provides a scale that allows us to ascertain the level to which an individual student identifies as a researcher at a discrete point in time, as well as to monitor change or growth in their researcher identity over time.

The hypothesis of the Researcher Identity construct map starts at the lowest level (Level 0) with the student being unaware of what research entails and no consideration for their own role in research. At Level 1, the student is a newcomer to the concept of research. At Level 2, the student explores the different aspects of research. At Level 3, the student be- gins to feel comfortable with their identity as a researcher. At Level 4, the student identifies as a researcher and integrates this into their larger self.

After several iterations based on the pilot data, think aloud (cognitive interviews) and exit interviews with students, teachers and subject matter experts, the final instrument consisted of 45 items and six Likert-type response categories (Strongly Disagree, Disagree, Slightly Disagree, Slightly Agree, Agree, and Strongly Agree). In the survey, a researcher is defined for the students as: "someone who conducts an organized and systematic investigation on a topic or question related to a scientific field." This definition was provided to all students at the beginning of the survey instrument. The researcher identity construct is considered one unified idea made up of four strands: Agency, Community, Fit and Aspiration, and Self (Table 2). The Agency strand relates to the extent of ownership an individual feels about conducting research. The Community strand measures the student's sense of belonging to the research community. The Fit and Aspiration strand measures the extent to which the researcher description aligns with the student's interests and future career goals. The Self strand measures the extent to which the student identifies himself/herself as a researcher.

The RIS was administered to each cohort of students at three time points - the first time before they began the program (pretest), the second after completion of the Summer Intensive (posttest 1) and the third time after successful completion of the full program year (posttest 2).

Table 2. Researcher Identity strands and related sample items.

\begin{tabular}{ll}
\hline \multicolumn{1}{c}{ Strand } & \multicolumn{1}{c}{ Sample Items } \\
\hline Agency & I can research issues independently. \\
& I can do research that helps people. \\
Community & I am a member of a research community. \\
& I am an important part of a group of researchers. \\
Fit and Aspiration & I would like to learn more about how to do \\
& research. \\
Self & I am interested in research. \\
& I have the skills to help do research. \\
& I consider myself a researcher.
\end{tabular}


Program Evaluation and Revision. Through an external program evaluator, we monitored program quality, progress and participant experiences using a combination of observations, written surveys and focus group interviews. Evaluation data used in this study were collected from three cohorts of the program. For each cohort, these data were gathered at three timepoints, through written surveys and focus group interviews at the beginning of the program, after the Summer Intensive, and again at the end of the program year.

For each of the three years included in this study, student participants participated in focus groups prior to the start of the program (pre) and following the final activity at the end of the program (post). Every student participated in a focus group of no more than five students and at times (due to scheduling) as few as two participants. Focus groups were audio recorded and transcribed and the interviewer also took notes. The questions for the post focus group interviews included open-ended (qualitative) and ratings scale (quantitative) questions. In addition to addressing health science content, the questions probed students' sense of themselves as researchers and agents of change, as well as their sense of community within SFHI. For example, questions included: "How, if at all, has your definition of a researcher changed through this program?," "How, if at all, do you feel you have grown as a researcher through SFHI?," and "On a scale from 1-5, with 1 meaning 'Not At All' and 5 meaning 'A Great Deal' (low to high), to what extent would you agree with the following statements: 'I feel a responsibility to make change in my community,' and 'I feel that I have the skills to make change in my community'?" Each participant was expected to contribute and the conversation was intentionally facilitated to ensure that every student had an opportunity to respond to a question or prompt. The vast majority of students' feedback on the program was positive, with occasional practical suggestions for the college counseling or resilience components - and not related to students' sense of community or sense of researcher identity.

Evaluation surveys used a combination of Likert-style and free-response items. The evaluation was designed to provide program staff immediate and actionable feedback that could be used to improve the program year-over-year. Likert items used a four point scale (Not at all, To a very little extent, To some extent, To a very great extent) and probed students' perceptions of (1) the quality of the program (e.g., I felt the Summer Intensive was well-planned and organized), (2) the program experience (e.g., I feel like I am a member of a research community), (3) their learning from the program (e.g., I have learned a lot about conducting research), and (4) ways they have benefitted from the program (e.g., I have made friendships with other students in the program). Open-ended questions asked what students valued about the experience, what went well, and what could be improved. Focus group interviews with small groups of students, fol- lowing the survey administration, allowed our evaluator to probe student responses on the survey more deeply, ultimately resulting in a more complete description of the students' experiences in the program and their perceptions of what they gained from their participation. Our external evaluator worked directly with participants and staff to gather data and shared anonymized findings with project staff both in a summary form for immediate, actionable feedback, as well as in annual reports. The annual reports included both quantitative and qualitative data that gave insights on participant and staff experiences, and student quotations from these data sources provided additional explanation and depth to shifts in student responses on quantitative surveys. Revisions and refinements were made to the program each year based on the evidence provided in the evaluation reports along with the program staff's own careful observations and reflections.

We initially used Miles and Huberman's (1994) and Miles et al.'s (2013) cluster coding techniques for analysis of the qualitative focus group data (in the form of transcriptions) and responses to open-ended survey items. The initial process of open coding served to conceptualize and categorize participants' responses. Coding prompted the team to revisit all aspects of the data, including themes that may not have seemed to be priorities during data collection but emerged as salient through coding (Saldaña, 2015). Revisiting the data repeatedly over the years allowed us to employ an axial coding strategy for developing an understanding of how the emphasis on strengthening community influenced student participants' confidence, interest, and engagement in STEM.

The project's research team was able to triangulate between the RIS survey responses and the anonymized mixed-methods evaluation data to build a deeper understanding of the outcomes of the San Francisco Health Investigators project. Supplementary Materials 1 presents a table that shows the relationship between the project's research questions, RIS items, and evaluation items that were used as a part of this study.

Longitudinal Follow-up. In addition to the evaluation surveys, students were asked to complete a longitudinal follow-up survey one-year post program, in late May of their senior year of high school. The May date is strategic as it is after the "commit" date for college enrollment, so students are likely to know their plans for the fall, but critically, they are still enrolled in their local schools, so school district issued email addresses are still active. This allows staff to reach students before they no longer have access to the primary email address we have on file, and update students' contact information so we can continue to connect with them in the future. The longitudinal follow-up survey asks a series of questions about students' plans post highschool graduation and, using Likert-style questions (5-point scale, Strongly Agree to Strongly Disagree), asks students to 
reflect on the impact of SFHI with respect to their self-efficacy, preparation for college, awareness of careers, and their future college and career goals. Finally, a series of open-response questions provides additional information that help program staff to understand students' response to the Likert questions. Response rates on the longitudinal follow-up survey were $79 \%$ (students from year one), 90\% (year two), and $58 \%$ (year three). Note that the year three survey was administered in May of 2020, as students were disconnected from school and missing the rituals of senior year due to the COVID-19 pandemic. Program staff followed-up individually through text messages and emails with any member of the year three cohort who did not complete the survey, so while survey data is incomplete with regards to Likert and open-ended responses, we were able to learn about college plans and career goals for $100 \%$ of students from this cohort. Data from the National Student Clearinghouse is used to provide additional evidence of student matriculation and continued enrollment in college.

\section{RESULTS}

Self-identification as a Researcher. We compared overall student outcomes on the RIS prior to the start of the program (pretest) with outcomes both at the end of the Summer Intensive (posttest 1) and at the conclusion of the year-long program (eleven months following the pretest, posttest 2) across a span of three years using the latent regression model (Mislevy, 1987; Verhelst and Eggen, 1989; Zwinderman, 1991). This analysis is derived from a Rasch-based analysis (Rasch, 1960). The Rasch model is in the Item Response Theory (IRT) family of psychometric models. To ensure a comparability of gains across cohorts, we used a Delta Dimensional Alignment (DDA; Schwartz, et al., 2017) technique, which allowed results from all three cohorts to be reported on a common metric, rather than a more traditional "common-item anchoring" approach due to the differences (across three years) in item scales of the items that have the same stem. Technical details are provided in Supplementary Materials 2.

Table 3 provides evidence that on average the growth of students' researcher identity was statistically significant, with a medium effect size for the years two and three cohorts. Note that a one logit increase is associated with an increase of: (1) $8 \%$ or 6 points (out of 70) for the year one cohort; (2) $11 \%$ or 14 points (out of 133) for the year two cohort; and (3) $8 \%$ or 13 points (out of 174) for the year three cohort. Effect size of growth was estimated using Cohen's d (Cohen, 1988). Notably this increase was present both at the completion of the Summer Intensive and persisted, though it moderated somewhat, through the end of the SFHI experience eleven months later. It is worth noting here that program organizers recognized after year one that additional work needed to be done in the project to build community
Table 3. Researcher Identity Growth (in logits): Pre to Post 1 and Pre to Post 2.

\begin{tabular}{llllllll}
\hline & & \multicolumn{3}{l}{ Pretest to Posttest 1} & \multicolumn{3}{l}{ Pretest to Posttest 2 } \\
\cline { 4 - 8 } Cohorts & $\mathrm{N}$ & Growth & $95 \%$ CI & $\begin{array}{l}\text { Effect } \\
\text { size }\end{array}$ & Growth & $95 \%$ CI & $\begin{array}{l}\text { Effect } \\
\text { size }\end{array}$ \\
\cline { 3 - 8 } Year 1 & 19 & 0.45 & $(-0.16,1.05)$ & 0.26 & -0.03 & $(-0.63,0.57)$ & 0.02 \\
Year 2 & 20 & $1.00^{*}$ & $(0.60,1.39)$ & 0.78 & $0.68^{*}$ & $(0.28,1.07)$ & 0.53 \\
Year 3 & 19 & $1.12 *$ & $(0.49,1.76)$ & 0.61 & $0.77^{*}$ & $(0.14,1.41)$ & 0.42 \\
\hline$* p<0.05$ & & & & & & &
\end{tabular}

among the participants and substantial effort was dedicated in subsequent years towards building a more inclusive research community. Figure 2 presents a visualization of the change in frequency of student responses to RIS items that highlight the role of students' relationships and peer community, the focus of this paper. A full frequency table of student responses across all three cohorts for all 45 RIS Likert response items can be found in Supplementary Materials 3, note that items shown in the Figure 2 graphs are marked in the table with a " $\uparrow "$ ".

Many researchers have found that an important component of identity development is recognition by others (including friends, parents, teachers, and mentors) (Carlone and Johnson, 2007; Aschbacher et. al 2010) and having peers with whom to share science interests can help solidify students' visions of themselves as scientists in the future (Stake and Nikens, 2005). Thus, it is striking to note that as a result of their participation in SFHI, students felt more accepted as researchers by their friends. This is indicated by responses to the Likert item "My friends see me as someone who is interested in research." We observed a positive change (average change of +3 students) in students responding "agree" or "strongly agree" to this statement (see Supplementary Materials 3 for full frequency table). A look at the change by year shows maximum positive change in year three ( +7 students). The numbers reported here and below for RIS items are the computed frequency of responses to each category (strongly agree to strongly disagree) in the pretest and posttest 2 for all three years. For example, for this item, we looked at the incremental change in the number of students who responded either strongly agree or agree from pretest to posttest for all the three years. Open-ended responses on the longitudinal follow-up survey provides more depth to this result. When asked "What aspects of SFHI were most valuable to you?", $70 \%$ of respondents included a statement about the value of the friendships they made in the program.

In addition to the data from the RIS, we identified one item on our end-of-program evaluation survey that addresses students' identity as researchers. Specifically, $72 \%$ of all participants (across the three years) agreed "to a great extent" with the statement "I feel like a researcher as a result of the SFHI program" (Table 4). However, consistent with the RIS findings, there are differences in the student responses 


\section{A. Agency \\ Year 1}

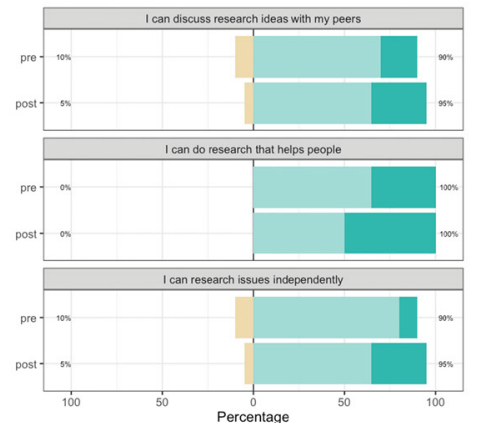

B. Community

Year 1

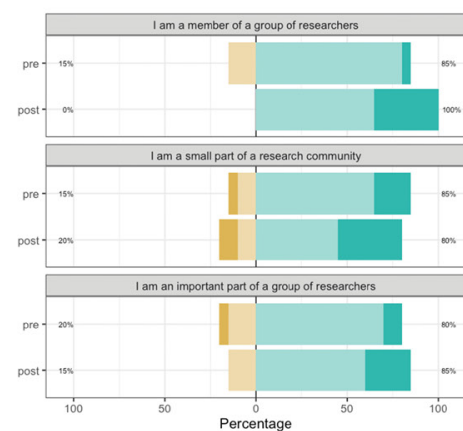

\section{Fit \& Aspiration}

\section{Year 1}

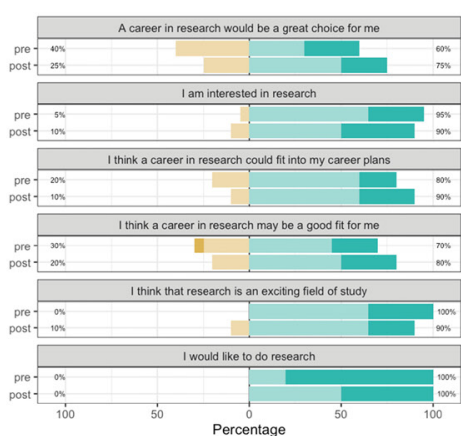

\section{Self}

\section{Year 1}

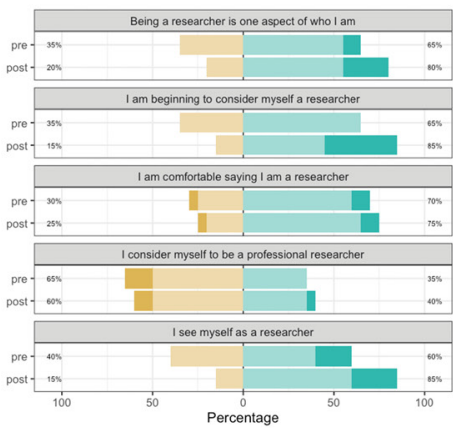

Year 2

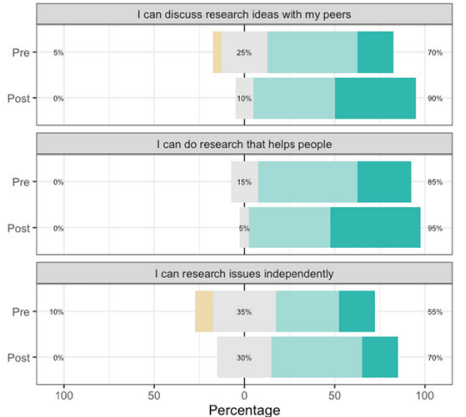

Year 2

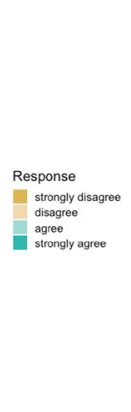

Year 3

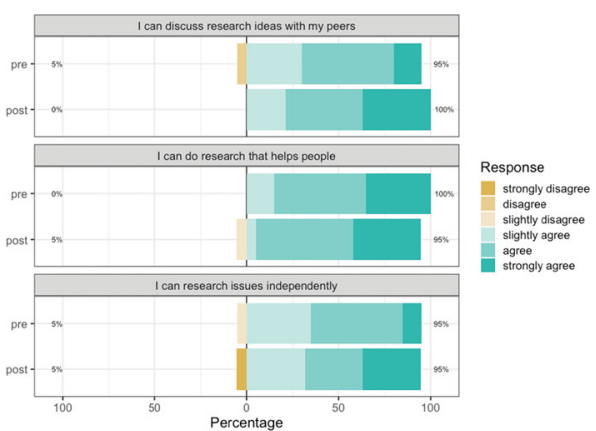

Year 3

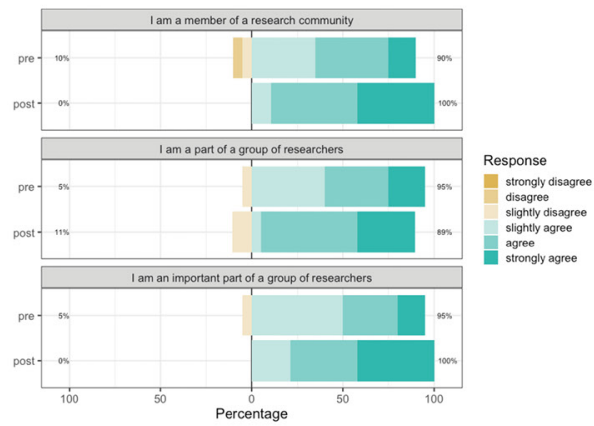

Year 3
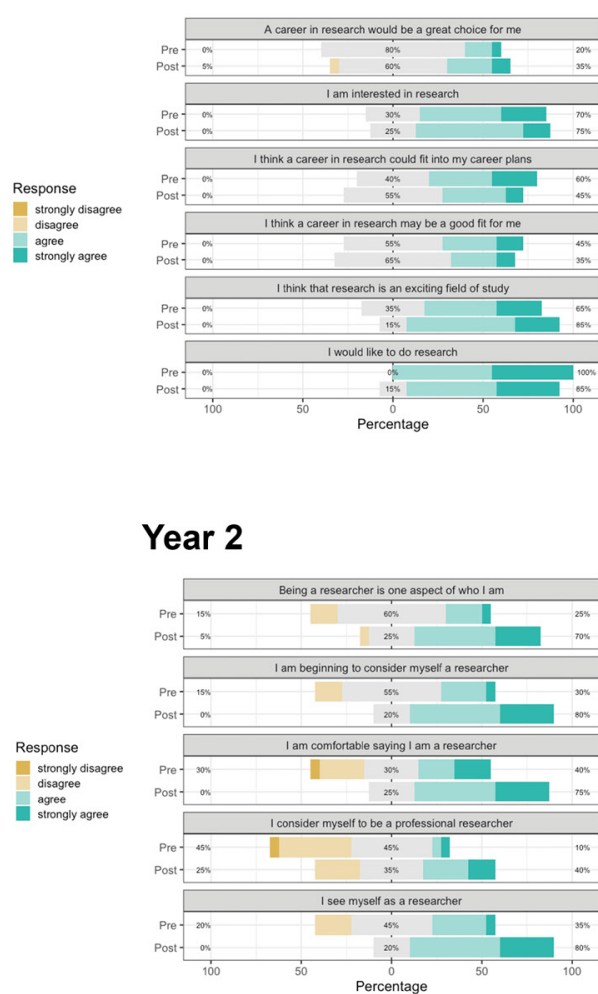

Year 2

Year 2

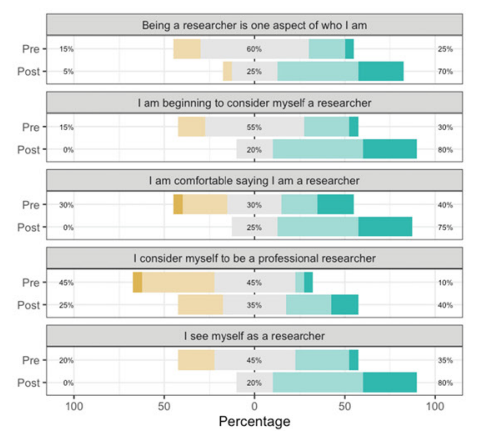

Response

Response
strongly disagro
disagrea

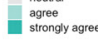

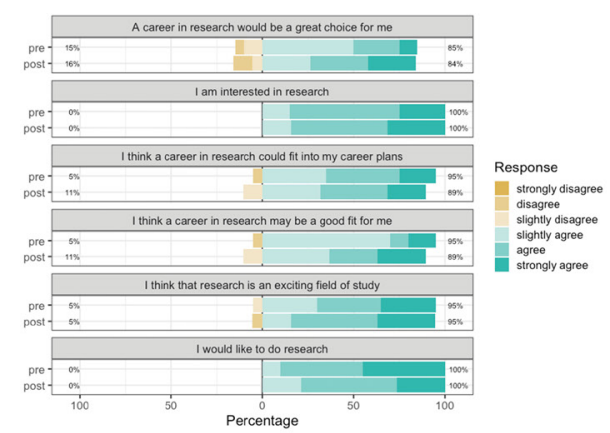

Year 3

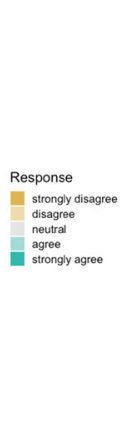

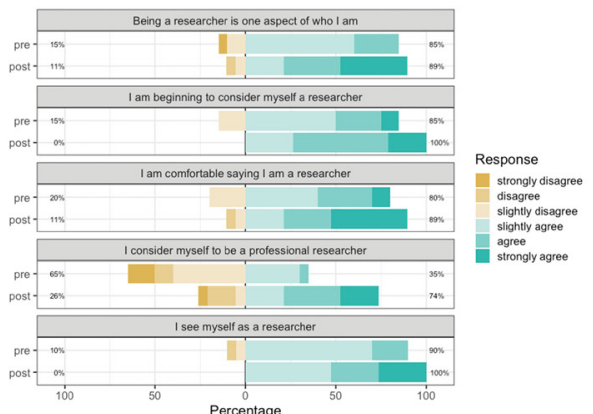

Figure 2. Frequency of Cohort Three Student Responses to Subset of RIS Likert Items. Items included in these graphs represent a subset of the RIS Likert items that highlight the role of students' relationships and the peer community. Each panel includes the Likert items for one of the four RIS strands: A. Agency; B. Community; C. Fit and Aspiration; and D. Self. 
Table 4. Frequency Table of Student Responses to Evaluation Survey Items.

\begin{tabular}{|c|c|c|c|c|c|c|c|c|c|c|c|c|}
\hline \multirow[t]{2}{*}{ ITEM } & \multicolumn{4}{|c|}{ Year $1(\mathrm{n}=18)$} & \multicolumn{4}{|c|}{ Year $2(\mathrm{n}=20)$} & \multicolumn{4}{|c|}{ Year $3(n=19)$} \\
\hline & $\begin{array}{c}\text { Not at } \\
\text { all }\end{array}$ & $\begin{array}{l}\text { Very } \\
\text { little }\end{array}$ & $\begin{array}{l}\text { Some } \\
\text { what }\end{array}$ & $\begin{array}{c}\text { To a great } \\
\text { extent }\end{array}$ & $\begin{array}{c}\begin{array}{c}\text { Not at } \\
\text { all }\end{array} \\
\end{array}$ & $\begin{array}{r}\text { Very } \\
\text { little } \\
\end{array}$ & $\begin{array}{l}\text { Some } \\
\text { what }\end{array}$ & $\begin{array}{c}\begin{array}{c}\text { To a great } \\
\text { extent }\end{array} \\
\end{array}$ & $\begin{array}{c}\begin{array}{c}\text { Not at } \\
\text { all }\end{array} \\
\end{array}$ & $\begin{array}{l}\text { Very } \\
\text { little } \\
\end{array}$ & $\begin{array}{c}\text { Some } \\
\text { what }\end{array}$ & $\begin{array}{c}\text { To a great } \\
\text { extent }\end{array}$ \\
\hline $\begin{array}{l}\text { I feel like a researcher as a } \\
\text { result of the SFHI program }\end{array}$ & 0 & 1 & 6 & 11 & 0 & 0 & 4 & 16 & 0 & 1 & 5 & 13 \\
\hline $\begin{array}{l}\text { I felt like a part of a strong } \\
\text { community of student } \\
\text { researchers in the SFHI program }\end{array}$ & 0 & 2 & 9 & 7 & 0 & 1 & 4 & 15 & 0 & 0 & 1 & 18 \\
\hline $\begin{array}{l}\text { I enjoyed the San Francisco } \\
\text { Health Investigators program }\end{array}$ & 0 & 0 & 4 & 14 & 0 & 0 & 0 & 20 & 0 & 0 & 0 & 19 \\
\hline $\begin{array}{l}\text { My voice was respected by } \\
\text { fellow students }\end{array}$ & & & t Asked & & & & Asked & & 0 & 0 & 6 & 13 \\
\hline
\end{tabular}

to this item in the first year when compared to students in the second and third years of the program. Specifically, while only $61 \%$ of students in the first year agreed "to a great extent" with this statement, $80 \%$ and $75 \%$ respectively of students in years two and three agreed "to a great extent" with this statement.

Exit focus group interviews conducted as part of the external evaluation provide descriptive evidence of how students' perceptions of who researchers are, what types of problems they study, and how researchers approach these problems have changed as a result of the program (see quotes, below). Critically, these data also present evidence for how this change in perception helped change students' perceptions of themselves as researchers.

"I used to think that researchers were more independent and they did their own independent work - I didn't realize that also you can be a researcher by communicating with your community and working with others. I never really had, um, those kinds of skills at first. And I feel like this internship helped me develop it or make my communication skills."

"I initially thought of a researcher as more someone who sits in a lab and I don't know, dissects something, or it looks at things and then writes down their findings. And over the summer that idea was kind of broadened because I learned that researchers also survey people and collect data on the public and help the public as well."

"As a researcher, I've grown in a lot of ways. I found out through the program you need others to help you know if your data is accurate. You need more people to do more trials. There might be trends you can't have seen if you are only doing your own trials."

Sense of Belonging to a Community. Both the program evaluation data and items from the RIS provided evidence that students in SFHI developed a sense of belonging to a community. One Likert-type question that was present on the end-of-program survey across all three cohorts specif- ically addressed this area - "I felt like a part of a strong community of student researchers in the SFHI program." In aggregate, across the three program years, $70 \%$ of respondents agreed "to a great extent" with this statement (Table 4). However, there is a significant variation in responses to this item when comparing year one to years two and three after more intentional community building activities were put in place. Only $38 \%$ of respondents in year one agreed "to a great extent" with this item whereas in years two and three, $75 \%$ and $95 \%$ respectively agreed "to a great extent" with this statement. In addition, students' responses to open-ended prompts on the evaluation survey provide additional insights into the students' sense of belonging to a program community. When asked about the most memorable part of the program, many respondents in the first year referred to the community, including "working with other people from different backgrounds and ethnicities," "working together as a team to achieve a common goal," "the people that I met," and "getting to know new people who like science just like me."

Conversely, when prompted about areas for improvement, many year-one respondents alluded to the need to "build a safe and strong community," for "better communication between students" and "more team building exercises and activities to get to know your cohort." In contrast, year two students expressed unanimous enthusiasm for the community building activities and conveyed the importance of these features to the project, as can be seen in the quotes below:

"I think the community building was extremely important in getting to know everyone. It really helped for us to work well together and make this project a success"

"I really enjoyed the team building activities and small group activities because it helped me bond with people in a comfortable way that was easy and included in the program"

The comments of year three respondents echo the sentiments of students in year two and highlight the impacts of the community building activities on the group. It was particularly notable how frequently students mentioned community across multiple open-ended prompts and how highly they regarded this feature of the program. For example, one open-ended question asked students to comment on what they enjoyed most about the Summer Intensive. Seventeen of the 19 students $(89 \%)$ who responded to this question mentioned the people and/or the community specifically:

"I think the program did a great job in welcoming everybody. The daily group activities were an effective way to bond with each other, and we grew to be 
a really close group. I would just say keep up with the activities, the program did a great job in making us feel welcome."

"I also felt very comfortable voicing myself with my peers. They were a welcoming group, and I felt as if I was a part of a family!"

"Something that I enjoy the most is being here with my colleagues and getting to present things with them and it's fun getting to know people that you don't usually go to school with"

"I enjoyed bonding with everyone in the program and making new friends with people I had never met before"

The end-of-program evaluation survey for year three included additional questions to further probe students' sense of safety and agency in the program. One of these Likert items provided greater insights about their experience in the community - "My voice was respected by fellow students" for which $100 \%$ of respondents agreed "to a good" or "to a great extent."

On the exit focus group interviews conducted as part of the external program evaluation, students' reflections provide further evidence on their sense of belonging to a community of researchers through SFHI:

"To be able to get the final results that we got, we needed our team... you know, we actually had to rely on each other... everybody had to do their part. If we had been alone, we wouldn't have gotten the results we did."

"I believe that the title of researcher is something you earn through experience working on projects in a community. It's like stripes you have to earn. When I consider myself a researcher, it's what I've learned from other researchers, so it touches back on the community and teamwork."

"I am surrounded by researchers-researchers that I like and who like science... people who look at things scientifically and break it down. So we all help and support each other during labs and analyzing data, and things like that."

Student responses on a longitudinal follow-up survey completed in late May of the students' senior year of high school (two years after the start of the program and one-year post program completion) provide further evidence of the strength of the SFHI community. Ninety percent of the respondents on this survey report keeping in touch with peers from SFHI, including nearly $40 \%$ of respondents stating that they continued to meet their SFHI peers "in real life," outside of school. In addition, $83 \%$ of respondents agreed or strongly agreed that the "friendships I made in SFHI were a positive influence on my life." This is eloquently described by one student who stated in a response to an open-ended prompt; "I believe that I can build relationships in college now that I have more experience with people who strive for success."

Finally, the Likert-type item from the RIS, "I am an important part of a group of researchers" also provides insights into students' connections to a research community as the program evolved over the three years. In aggregate across all three years, we observed a positive change (average change +3.67 students) in students responding "agree" or "strongly agree" to this statement. A look at the change by year shows no change in year 1 (-1 student), and a positive change in years two ( +5 students) and three ( +7 students). In addition, we analyzed the average change for all community strand items and observed a similar pattern of change, where a positive change of +20 students was observed on average for the three program years with positive change observed in years two and three. This is striking as it suggests that the more explicit time devoted to community building in the program positively impacted the student experience and outcomes.

\section{Confidence and Self-efficacy in Science and Research.} Evidence for the impact of the program on students' confidence and self-efficacy can be found in student responses on the RIS, as well as in qualitative data from the end-of-program evaluation survey, and both Likert-style and open-ended items on the longitudinal follow-up survey. From the RIS, changes in students' responses pre to posttest 1 on the following three items indicate change in confidence and self-efficacy: "I can discuss research ideas with my peers;" "I can do research that helps people;" and "I can research issues independently."

We observed a positive change in students responding "agree" or "strongly agree" to all three statements for each year of the study with the exception of the second statement ("I can do research that helps people") for year one, which remained high from the time of the pretest to posttest 1. Especially notable was the year two cohort. Fourteen students either agreed or strongly agreed at the time of the pretest, and 18 students agreed (either agreed or strongly agreed) with the statement about discussing research ideas with their peers at the time of the posttest 1 administration (I can discuss research ideas with my peers).

Qualitative data from evaluation surveys administered at the end of the program year, provide additional evidence for an increase in students' confidence and self-efficacy in science and research among students in years two and three:

"The most important take-away for me was that I 
went completely out of my comfort zone through the help of this program. I have learned a lot more about myself and my capabilities. I have also gained a lot of confidence in my research skills. I feel a lot more connected to my community and I know that I made a positive impact on people's lives which is my greatest achievement so far."

"This program is what has made me more confident in myself. I have confidence in my own skills and I can work well with others. It is one of the reasons I am going into the health field and one of the reasons that I can do well in any challenges I face."

"I think the most important takeaway for me in this program is that we are not too young to make a difference in our communities. I remember when I was accepted into the program, I did have some doubts and insecurities whether I was smart enough or good enough to do this, but I've learned that I can. With the help of others, students can make a difference."

Longitudinal survey data also provides striking evidence for the impact of SFHI on students' confidence and self-efficacy in science and research. One year after completing the program, $91 \%$ of program alumni agreed or strongly agreed that as a result of participation in SFHI their self-confidence increased. Two other Likert-items in the longitudinal survey shed additional light on specific dimensions in which students perceived their confidence to have increased as a result of their participation in the program: $96 \%$ of SFHI alumni agreed or strongly agreed that as a result of their participation in SFHI they became more comfortable communicating in classes or groups and $91 \%$ agreed/strongly agreed that they became more comfortable communicating with adults. Finally, 79\% reported that participation in the program increased their expectations for what they could achieve in life. In response to open-ended questions, students shared some of the ways SFHI had helped them to build their confidence and affected their expectations for the future:

\section{"The program helped me communicate with people better all thanks to the survey taking we conducted. It also helped me improve my public speaking skills by the mini presentations we did in the program."}

"SFHI made me believe that college is possible. Having a large group of supportive friends from SFHI has taught me that college and hardships would be easier with a network to hold on to."

Engagement and Interest in Science and Research. The recruitment of students into the program was unbiased with respect to student's inclination to pursue a career in science and research, i.e., to be selected as a participant in our pro- gram, demonstrating interest in science and research was not mandatory, rather we sought students interested in exploring science and research in a new context. Irrespective of students' prior interest in science, an overwhelming majority of students reported that they enjoyed being a part of the program. Specifically, each year, students were asked on the program evaluation exit surveys to what extent they enjoyed being a part of SFHI, on a scale from one to four, (one = not at all and four $=$ a great deal). In year one, $78 \%$ of students responded with the maximum rating of four and the remaining $22 \%$ responded with the second-highest rating of three. After program leaders placed a greater emphasis on community-building among students in cohorts two and three, these ratings increased; $100 \%$ of students in years two and three responded with the highest rating of four. Moreover, evidence from the RIS, the end-of-program evaluation surveys, and longitudinal surveys provides evidence that students' interest in pursuing careers in science and research increased after the SFHI experience and that this interest persisted at least one-year post-program.

Two items from the "Fit and Aspiration" strand of the RIS provide quantitative evidence for change in students' interest in research. While the overall outcome was consistent across three years, we noticed a larger change from pretest to posttest in the year three than other years. Because of the SFHI intervention, (a) student aspirations to pursue a research-related degree in college increased as indicated by response to the item "I plan to get a research-related degree in college." We observed a positive change (average change of +2.33 students) in the frequency of students responding to "agree" or "strongly agree" to this statement. A look at the change by year shows maximum change in year three (+5 students). (b) Students' inclination to follow their own research interests also increased as indicated by response to the item "I plan to follow my own research interests in the future" We observed a positive change (average change of +4 students) in students responding to "agree" or "strongly agree" to this statement. Maximum change was recorded in year three (+7 students).

Comments from students in years two and three on the end-of-program evaluation survey provide descriptive evidence for the influence of the SFHI community on their interest in pursuing a career in science or health.
"Being a part of this program influenced me to lean towards working in the public health field, because I like helping people." "Before I started this program, the only career ideas
I had were either gaming or graphic design. But this
program showed me how the medical field works and
that it isn't as scary as I thought it would be. Now I'm
looking into Sports Medicine because I really love
sports and health. It's the best of both worlds." 
On the longitudinal follow-up survey, seventy-eight percent of program alumni agreed or strongly agreed that participation in the program increased their interest in science. For example, one respondent remarked, "[SFHI] made me more interested in science and helped me figure out what I want to study." Eighty-four percent of SFHI alumni stated that as a result of SFHI their motivation to work hard in school increased. Notably, $40 \%$ of program alumni responded that they changed their course-taking in their senior year to include more rigorous science and math classes as a result of SFHI. As one student stated: "It made me want to learn about data, so I took AP Statistics." It is worth noting that $74 \%$ of the students who did not report taking additional science and math classes stated that they were unable to do so because either 1) their school did not offer advanced courses in these fields or 2) their schedule had already been determined prior to the summer experience and they were not able to change it in the fall. In addition, $100 \%$ of SFHI alumni state that as a result of their participation in SFHI, they better understand the work of researchers. In their open-ended responses, students reflected on the role that SFHI played in exposing them to new fields of study and helping them to identify their major in college and future career path in science and research.

\section{"SFHI was my first exposure to the science/health field and I found that I really enjoyed it through the program."}

"SFHI has helped show me that a career in public health can be fun and beneficial and have a super big impact on the communities. And I have always wanted to be someone that helps others and I always thought that was just through being a doctor or police or firefighter, but I realized that careers in public health also play a major role in helping the public."

At least $92 \%$ of the SFHI alumni from across the three study years matriculated directly to college in the fall following high school graduation (Table 5). This number far

Table 5. College Matriculation of SFHI Alumni.

\begin{tabular}{lcccc}
\hline & Year 1 & Year 2 & Year 3 & TOTAL $(\%)$ \\
\hline $\begin{array}{l}\text { Community } \\
\text { College }\end{array}$ & 4 & 3 & 1 & $7(12 \%)$ \\
$\begin{array}{l}4-y e a r \\
\text { Public }\end{array}$ & 7 & 14 & 16 & $37(64 \%)$ \\
$\begin{array}{l}\text { 4-year } \\
\text { Private }\end{array}$ & 5 & 2 & 2 & $9(16 \%)$ \\
$\begin{array}{l}\text { Armed } \\
\text { Services }\end{array}$ & $1 *$ & 0 & 0 & $1(2 \%)$ \\
Unknown & 2 & 1 & 0 & $3(5 \%)$ \\
\hline *Sturtiom
\end{tabular}

*Student is matriculating to a 4-year university in Fall 2021. exceeds the nationwide rate of college matriculation among students who would be first in their family to attend college $(58 \%)$ as well as that of students whose parents hold a Bachelor's degree (78\%) (NCES, 2018). While SFHI students report that SFHI influenced their confidence in their ability to be successful in college, their choice of where to apply, and their competitiveness as a college applicant, it is beyond the scope of this study to ascribe causality to this outcome.

\section{DISCUSSION}

Practical Use of the Researcher Identity Scale. The RIS used in this study was developed using the BEAR Assessment System (BAS) (Wilson, 2005). While most frequently used for content assessments, the BAS is a useful framework for developing affective student assessments, such as the RIS. Assessments developed in this system provide leveled understanding of where an individual student falls with respect to the affective trait being assessed (i.e., Researcher Identity), and in combination with the Construct Map, provide actionable information that help inform program refinement to promote student growth. In this paper we describe how the RIS revealed how few students in the first year of the program felt a part of a strong community of researchers and ultimately students in this cohort showed limited growth in their Researcher Identity. In response to these findings, program staff in subsequent years dedicated significantly more effort to community building. This investment of time resulted in substantial growth in students' agreement to this item and a corresponding increase in students' overall Researcher Identity. Thus, this study provides a concrete example of how the BAS, and the system's tenets of aligning the Construct, assessment items, and curriculum can provide formative feedback to improve a program, while also helping to understand a program's summative outcomes. While sustainability of programs is always a challenge after funding sunsets, we believe that the RIS is a tool that may be of broad use in other science education programs and indeed, at this writing, at least six informal science programs have expressed interest in using the RIS.

Importance of Community on Students' Researcher Identity, Engagement, and Belonging. Improving the state of science education in the United States has become a national priority, with the goal of increasing diversity in STEM fields as well as meeting demands for the STEM workforce. One response to this problem has been the implementation of STEM enrichment programs designed to increase the number of students that complete STEM majors, enter graduate programs in science, and enter STEM careers. Current research indicates enrichment programs can have positive effects for student performance, degree completion, interest in science and graduate enrollment (Salto et al., 2014; Rohr- 
baugh and Corces, 2011; Kabacoff et al., 2017; Witzel et al., 2020). Moreover, research suggests that beyond improving performance in STEM, and providing access to research experiences and faculty mentoring, enrichment programs may also increase the degree to which students identify as scientists (Merolla and Serpe, 2013).

In the development of such enrichment programs, it is critical to consider how such an experience can shape and impact students' identity development. Introducing pre-college students to STEM environments often involves youth navigating new knowledge, practices and culture. Students partake in situational learning (Lave and Wenger, 1991) where they take on the identity of being an apprentice or novice to learn in practice and develop expertise. However, the success of learning and identity formation in these environments is highly dependent on the student's acceptance or rejection of the social position accorded by the scientific community and its cultural norms. The acceptance, engagement or resistance of their accorded position, described as an identity-in-practice in the Tan and Barton (2008) framework, is impacted by the students' cultural context and other identities-in-practice that they hold. They further describe this challenge as:

On initial entry into a figured world, novices gain social positions that are accorded by the established members of that world. How novices choose to accept, engage, resist or ignore such cues shape their developing identity-in-practice and determine the boundaries of their authoring space, which is driven by a sense of agency. In the struggle to establish an identity in a new figured world, it is important to consider the influence of the other worlds in which one simultaneously inhabits.

Here we aimed to create a hybrid space (Barton) to engage students in STEM research and to provide opportunities to transform their identities-in-practice, in particular to develop a researcher identity by involving youth as co-researchers and co-designers of a year-long collaborative public health research project with a group of peers. In creating this space, program staff sought to be responsive to students' needs and to formative evaluation data allowing the continuous refinement of the program. The challenges that arose in the program and how the program adjusted to meet these challenges will be addressed in more detail in a later paper.

The research findings presented in this paper indicate that for the SF Health Investigators program, a continued emphasis on peer relationships and community development coupled with an experience that elevates students' cultural knowledge and expertise has had a statistically significant impact on students' Researcher Identity with a medium effect size, and also an impact on engagement in the program and their sense of belonging in the program community and ultimately the research community as a whole. Our analysis suggests that observed increases in engagement and sense of belonging to the community between the first-year cohort and subsequent cohorts improved with the increased emphasis on community building. Furthermore, we observed that students' sense of belonging in the community and their interest in STEM, their self-efficacy, and their identities as researchers grew during the SFHI program.

There may be concern that programs like SFHI, that leverage and explicitly value students' many identities rather than encouraging assimilation into a "traditional" scientific environment might result in an idealized view of STEM environments and thus not adequately prepare students to succeed in more traditional STEM settings. However, we have found this not to be the case as our longitudinal survey results suggest that the impact of this experience can be long-lasting and broad in scope. Despite the fact that participants leave the unique STEM learning community of SFHI to enter other more traditional STEM spaces in school, as high school seniors, and subsequently as college students, they are able to view themselves and those spaces in a new light. Specifically, alumni one-year post-program completion report increased expectations for what they can achieve in their lives, increased motivation to pursue more rigorous study and science coursework and a strong sense of belonging to a life-long network of peers with whom they share a STEM and research identity. Moreover, program alumni view the SFHI community as an important and valuable network and resource for persisting through hardships and challenges they will face in the future. This is an exciting and encouraging outcome given the need to address the well-documented disparities for degree completion rates among minoritized undergraduates and their persistence in STEM majors and careers. These findings have significant implications for designing STEM experiences for youth, both in terms of STEM learning and in terms of cultivating long-term interest and engagement in STEM careers.

\section{ASSOCIATED CONTENT}

Supplemental material mentioned in this manuscript can be found uploaded to the same webpage as this the manuscript.

\section{AUTHOR INFORMATION Corresponding Author}

Bon Koo.ben.koo@berkeley.edu

\section{Author Contributions}

The manuscript was written through contributions of all authors. All authors have given approval to the final version of the manuscript. 


\section{ACKNOWLEDGMENTS}

The San Francisco Health Investigators program and the Researcher Identity Survey both evolved over several years. We are extremely grateful to our SFHI students, from whom we learned so much. You continue to inspire us every day. We are grateful to the efforts of many who made this work a reality, Jenna Bernard worked tirelessly on the development of SFHI, Canan Mesutoglu played an important role in the early development of the RIS, Mary Kreger supported students' resiliency, Michelle Channel helped students understand and navigate the college application and financial aid process, and both Luz Marin and Solange Arbesú-Sala supported the project behind the scenes. Irene Faye Duller and Julie Munsayac, the graphic design team from Otherwise, helped students recognize the power in their creative voices. Khanh Tran and our Peer Leaders, Rashaad Ali, Kimberly Hernandez, Yrah Macahilas, Joanne Lin, Jinglan Liu, Tiffany Ngo, Henry Nguy, Ysak Ordonez, and Kevin Sanchez supported our efforts to build student communities.

\section{FUNDING SOURCE}

This work was funded by an NIH Science Education Partnership Award (grant \#8R25GM129194) and all research was approved by the UCSF IRB (study \#14-15463).

\section{ABBREVIATIONS}

BEAR: Berkeley Evaluation and Assessment Research; CBPR: Community-based Participatory Research; DDA: Delta Dimensional Alignment; IRT: Item Response Theory; RIS: Researcher Identity Scale; SEP: Science and Health Education Partnership; SHFI: San Francisco Health Investigators; UCSF: University of California, San Francisco; YPAR: Youth Participatory Action Research

\section{REFERENCES}

Aikenhead, G.S. (2001). Students' ease in crossing cultural borders into school science. Science Education, 85, 180-188. DOI: https://doi.org/10.1002/1098237X(200103)85:2\%3C180::AID-SCE50\%3E3.0.CO;2-1

Aschbacher, P. R., Li, E., and Roth, E. J. (2010). Is science me? High school students' identities, participation and aspirations in science, engineering, and medicine. Journal of Research in Science Teaching, 47(5), 564-582. DOI: $10.1002 /$ tea.20353

Bathia, S., Morell, L., Smith, R., Koo, B. and Wilson, M. R. (2020, April 17 - 21) Measuring High School Students' Self-Perception as a Researcher: Development and Validation of the Researcher Identity Scale [Poster Session]. AERA Annual Meeting San Francisco, CA http://tinyurl. com/sajb3fx (Conference Canceled)
Brickhouse, N.W., and Potter, J.T. (2001). Young women's scientific identity formation in an urban context. Journal of Research in Science Teaching, 38(8), 965-980. https://doi. org/10.1002/tea.1041

Carlone, H. B., and Johnson, A. (2007). Understanding the science experiences of successful women of color: Science identity as an analytic lens. Journal of Research in Science Teaching. 44, 1187-218. https://doi.org/10.1002/tea.20237

Cohen, J. (1988). Statistical Power Analysis for the Behavioral Sciences. Routledge. ISBN 978-1-134-74270-7.

Eccles, J.S., Adler, T.F., Futterman, R., Goff, S.B., Kaczala, C.M., Meece, J.L., and Midgley, C. (1983). Expectancies, values, and academic behaviors. In J.T. Spence (Ed.), Achievement and achievement motivation (pp. 75-146). San Francisco, CA: W.H. Freeman.

Hill, P. W., McQuillan, J., Spiegel, A. N., and Diamond, J. 2018. Discovery Orientation, Cognitive Schemas, and Disparities in Science Identity in Early Adolescence. Sociological Perspectives, 61(1), 99-125. https://doi. org/10.1177/0731121417724774 PMC5860849

Kabacoff, C., Srivastava, V., and Robinson, D.N. (2017). A Summer Academic Research Experience for Disadvantaged Youth. CBE - Life Sciences Education: 12(3). Available from: https://doi.org/10.1187/cbe.12-12-0206

Lave, J., and Wenger, E. (1991). Situated learning: Legitimate peripheral participation. New York, NY: Cambridge University Press.

Lee, R.M., and Davis III, C. (2000). Cultural orientation, past multicultural experience, and a sense of belonging on campus for Asian American college students. Journal of College Student Development, 41(1), 110-115.

Miles, M.B. and Huberman, M.A. (1994). Qualitative Data Analysis, 2nd ed., Sage, Thousand Oaks, CA.

Miles, M.B., Huberman, A.M. and Saldana, J. (2013). Qualitative Data Analysis: A Methods Sourcebook (Incorporated), SAGE Publications, Thousand Oaks, CA.

Mislevy, R. J. (1987). Exploiting auxiliary information about examinees in the estimation of item parameters. Applied Psychological Measurement, 11(1), 81-91. DOI: https://doi. org/10.1177/014662168701100106

Merolla, David and Serpe, Richard. (2013). STEM enrichment programs and graduate school matriculation: The role of science identity salience. Social psychology of education: an international journal. 16. 575-597. DOI: $10.1007 /$ s11218-013-9233-7

Morell, L., Bathia, S., Koo, B. and Wilson, M., Smith, R., (2020) A 12-Item Survey to Measure "Identity as a Researcher" NARST Annual Meeting Portland, OR (Conference Canceled) 
NCES (National Center for Education Statistics). (2018). First-Generation Students: College Access, Persistence, and Postbachelor's Outcomes. Statistics in Brief Report. Authors: Cataldi, E.F., Bennett, C.T., and Chen, X. Retrieved from: https://nces.ed.gov/pubs2018/2018421.pdf

Rasch, G. (1960). Probabilistic models for some intelligence and attainment tests. (Copenhagen, Danish Institute for Educational Research), expanded edition (1980) with foreword and afterword by B.D. Wright. Chicago: The University of Chicago Press.

Rohrbaugh, M.C., and Corces, V.G. (2011). Opening Pathways for Underrepresented High School Students to Biomedical Research Careers: The Emory University RISE Program. Genetics 189(4): 1135-1143; https://doi.org/10.1534/genetics.111.132126

Saldaña, J. (2015). The Coding Manual for Qualitative Researchers, Sage, Thousand Oaks, CA.

Salto, L. M., Riggs, M. L., Delgado De Leon, D., Casiano, C. A., and De Leon, M. (2014). Underrepresented minority high school and college students report STEM-pipeline sustaining gains after participating in the Loma Linda University Summer Health Disparities Research Program. PloS One, 9(9), e108497. DOI:10.1371/journal.pone.0108497

Schwartz, R., Ayers,E., and Wilson, M. (2017). Mapping a Data Modeling and Statistical Reasoning Learning Progression Using Unidimensional and Multidimensional Item Response Models. Journal of Applied Measurement, 18(3), 268-298.

Stake, J. E., and Nickens, S. D. (2005). Adolescent Girls' and Boys' Science Peer Relationships and Perceptions of the Possible Self as Scientist. Sex Roles: A Journal of Research, 52(12), 1-11. https://doi.org/10.1007/s11199-005-1189-4

Tan, E., and Barton, A, C. (2008) Unpacking science for all through the lens of identities-in-practice: the stories of Amelia and Ginny. Cultural Study of Science Education, 3, 43-71. DOI: https://doi.org/10.1007/s11422-007-9076-7

Verhelst, N. D., and Eggen, T. J. H. M. (1989). Psychometrische en statistische aspecten van peilingsonderzoek [Psychometric and statistical aspects of assessment research], PPON-rapport, 4. Arnhem: Cito.

Witzel, L., MacCormack, J.A., Nielsen, K.M., and Smith, R. (2020). Fostering pathways: 30 Years of inspiring high school students to pursue science careers through biomedical research experiences. Journal of STEM Outreach, 3(2). https://doi.org/10.15695/jstem/v3i2.01

Wilson, M. (2005). Constructing Measures: An Item Response Modeling Approach. Mahwah, NJ: Lawrence Erlbaum Associates.

Zwinderman, A. H. (1991). A generalized Rasch model for manifest predictors. Psychometrika, 56(4), 589-600. https:// doi.org/10.1007/BF02294492 